JOURNAL OF GEOPHYSICAL RESEARCH, VOL. 88, NO. B11, PAGES 9500-9512, NOVEMBER 10, 1983

\title{
SHOCK COMPRESSION OF SINGLE-CRYSTAL FORSTERITE
}

J. Peter Watt ${ }^{1}$ and Thomas J. Ahrens

Se 1smological Laboratory, California Inst1tute of Technology

Abstract. Dynamic compression results are reported for single-crystal forsterite loaded along the orthorhombic $a$ and $c$ axes to pressures from 130 to $165 \mathrm{GPa}$. Hug on iot states for the two axes are well described by a sing le curve offset to densities $0.15-0.20 \mathrm{~g} / \mathrm{cm}^{3}$ lower than earlier data for single-crystal forsterite shocked along the $b$ axis above $100 \mathrm{GPa}$. Earlier data of Syono et al. [1981a] show marginal support for similar b-axis behavior in the mixed-phase region from 50 to 92 $\mathrm{GPa}$. Thus shocked forsterite is most compressible in the $b$ direction for the mixed-phase and highpressure regines ( $P>50 \mathrm{GPa}$ ). These data represent the highest pressures for which shook properties have been observed to depend on crystal orlentation. Theoretical hug on iots for mixed-oxide and perovskite-structure high-pressure assemblages of forsterite calculated from recent experimental data are virtually identical and agree with the $b$-axis data. The a- and c-axis data are also consistent with both high-pressure assemblages because uncertainties in equation of state parameters produce a broad range of computed Hug oniots. Our calculated "average" Hug on lot is up to 0.13 $\mathrm{g} / \mathrm{cm}^{3}$ less dense than the preferred theoretical Hug oniots, in agreement with earlier measurements on dense polyorystalline forsterite. Interpola$t$ ion between the single-crystal forsterite Hugoniots and fugonlots for fayalite and $\mathrm{FO}_{45}$ gives Fo ${ }^{2}$ Hug on iots bracketing Twin Sisters dunite data not previously well flt by systematics. Release paths are steep for the $a$ and $b$ axes but c-axis release paths are much shallower. Hug o$n$ iot elastic limits measured for the $a$ and $b$ axes are in good agreement with previous data of Syono et al.; however, the present data for the a axis reveal a triple wave structure: two deformational shock waves as well as the elastic shock, a feature not previously found. The second shock, with amplitude about $9 \mathrm{GPa}$ and a shock temperature of about $350^{\circ} \mathrm{K}$, could perhaps be explained by the forsterite $\alpha \rightarrow \beta$ or $\gamma$ phase transformation.

\section{Introduction}

Magnesium-rich olivines are believed to be the dominant mineral component of the upper mantle. Acquisition of data on the high-pressure behavior of olivines is of great importance for interpreting mantle velocity and density profiles derived from inversion of seismic travel time and normal mode data. Until recently, experimental pressures

1 Now at Department of Geology, Rensselaer Polytechnic Institute.

Copyright 1983 by the American Geophysical Union.

Paper number 381078 .

$0148-0227 / 83 / 003 B-1078 \$ 05.00$ comparable to those in the lower mantle below 670 $\mathrm{km}$ could be reached only in shock-wave studies such as those of Trunin et al. [1965], MoQueen et al. [1967], and Ahrens and Petersen [1969] on natural forsterite-rich olivines; McQueen and Marsh [1966] and Ahrens et al. [1971] on synthet10 forsterite aggregates of 2-5\% porosity; MoQueen [1968] and Marsh [1980] on synthetic forsterite aggregates of less than $1 \%$ porosity; and Jackson and Ahrens [1979] and Syono et al.[1981a] on synthetic forsterite single crystals. In general, these data at pressures over about $80 \mathrm{GPa}$ were interpreted as consistent with an isochenical mixture of oxides, $(\mathrm{Mg}, \mathrm{Fe}) 0$ (rock salt structure) and $\mathrm{SiO}_{2}$ (stishovite) [Birch, 1952], although Jeanloz and Ahrens [1977] and Jackson and Ahrens [1979] argue for high-pressure phases of olivines denser than the simple close-packed oxide mixture.

In recent years, this high-pressure region of olivine has become accessible to static compression studies combined with in situ $X$ ray work. Results of Liu [1975, 1976a, b], Ito [1977], Mao et al. [1977], and Sawamoto [1977] demonstrate that at pressures and temperatures relevant to the mantle below $670 \mathrm{~km}$, magnesium-rich ollvines, pyroxenes, and garnets transform to mxtures of ( $\mathrm{Mg}, \mathrm{Fe}) \mathrm{O}$ and $(\mathrm{Mg}, \mathrm{Fe}) \mathrm{SHO}_{3}$ (perovskite structure) several percent denser than the isochemical ox1des.

Several shock recovery experiments have been performed to seek evidence for formation of this high-pressure perovskite-structure (pv) phase in shocked olivine. Jeanloz et al. [1977] observed formation of glassy regions associated with areas having high dislocation density in single-crystal peridot shocked above $56 \mathrm{GPa}$ and speculated that this glass may have formed upon retransformation of a high-pressure phase upon releasing from peak shock pressure. Jea nloz [1980] und ertook opt1cal and electron microscopic and infrared spectroscopic studies of recovery products of singlecrystal peridot loaded to pressures up to $76 \mathrm{GPa}$ and found no evidence to support formation of a high-pressure phase. There was extensive plastic deformation but no trace remanent h1gh-pressure phases, shock-induced melting, recrystallization or recovery on unloading. From this result, Jeanloz proposed a crystallographically-based model for the shock behavior of olivine that did not require a reconstruotive phase transformation. In the model the olivine crystal could be viewed as sets of nearly hexagonally close-packed sheets of oxygen ions with the hexagonal axis along the olivine orthorhombic a axis and the cations interlayered among the oxygen layers. Shock compression distorts the oxygen layers around the intervening cations and leads to the observed high Hugoniot densities. The model predicts that olivine will be most compressible along the a axis, with lower, but roughly equal, compressibilities for the $b$ and $c$ axes. 
Syono et al. [1981b] carried out transmission electron microscopy, electron diffraction, and chemical work on single-crystal forsterite loaded to pressures between 78 and $92 \mathrm{GPa}$ and found formation of precipitates with MgO composition and glassy regions of about $\mathrm{MgSiO}_{3}$ composition. They interpreted this as either profduction of $\mathrm{MgSiO}_{3}$ (pv) and MgO at high pressures or as incongruent melting of forsterite to produce MgO crystals and $\mathrm{MgSiO}_{3}$ melt. Jakubith and Seidel [1982] shocked an ouphacitic eclogite (58\% omphacite, $17 \%$ kyanite, 17\% gamet and 4\% quartz) and, using $X$ ray diffraction on the recovered material, inferred the presence of $\mathrm{MgSiO}_{3}(\mathrm{pv})$.

Thus, while the evidence for formation of a high-pressure phase with perovskite structure in shock-compressed olivines is not unambiguous, the available data, combined with static compression results, are fairly compelling. The lower inantle below $670 \mathrm{~km}$ may well be dominated by perovskitestructure sillcates, although Anderson [1977] and Jeanloz and Thompson [1983] argue that an ollvine (spinel)-perovskite transition alone is insufficient to account for the sharpness of the $670 \mathrm{~km}$ discontinuity. Jeanloz and Thompson support the presence of a chemical discontinuity as well. Anderson [1970], Anderson et al.[1971], Gaffney and And erson [1973], Burdick and Anderson [1975], and Butler and Anderson [1978] argue for a lower mantle enriched in silicon relative to the upper mantle, a conclusion supported by results of Watt and Ahrens [1982], based on current high-pressure data.

In th1s paper, we present results for singlecrystal forsterite shock-loaded along the $a$ and $c$ axes to pressures up to $165 \mathrm{GPa}$. Combining these data with b-axis results of Jackson and Ahrens [1979], we can test the prediction of Jeanloz's [1980] model that olivine should be most compressible along the a axis. We also compare our data to a high-pressure phase Hugoniot calculated from static compression and ultrasonic data on $\mathrm{MgO}$ and $\mathrm{MgSiO}_{3}(\mathrm{pv})$. We flind that a- and c-axis Hugoniots are essentially colncldent and displaced to densities $0.15-0.20 \mathrm{~g} / \mathrm{cm}^{3}$ lower than those for the $b$ axis. Data for all three axes are consistent with formation of either a high-pressure mixed-oxide or perovsicite-structure assemblage, within the uncertainty in the computed Hug oniots. Our preferred interpretation, however, is formation of a high-pressure assemblage somewhat less dense than mixed oxides or perovskites.

\section{Experimental Details}

The experiments were executed in a manner similar to those of Jackson and Ahrens [1979]. Synthetic forsterite single crystals (Union Carbide Corporation, Crystal Products Division) were used with the shock propagation direction along either the orthorhombic $a$ or $c$ axis ( $b<c<a)$. Sample densities were measured by Archimedes, otechnique with immersion in toluene. The average density was $3.226 \mathrm{~g} / \mathrm{cm}^{3}$; standard deviation was 0.002 $\mathrm{g} / \mathrm{cm}^{3^{3}}$ ( 6 samples). The samples, 2.8-3.3 ram thick, were lapped to with in +0.002 mm of uniform thickness and mounted on $0 . \overline{5}-\mathrm{mm}-$ thick tantalum driver plates with an array of fused quartz arrival mirrors. Lexan projectiles with 1.5 to $2.5-\mathrm{mm}$-thick tantalum flyer plates were acceleratated in a two-stage light-gas gun to velocities between 5.3 and $6.3 \mathrm{~km} / \mathrm{s}$. Projectile velocities were measured using two 15-ns duration flash $x$-ray sources and $0.01-\mu \mathrm{s}$ electronic counters to record the interflash time interval over a path of about $350 \mathrm{~mm}$ Imnediately in front of the stationary target assembly. Accuracy of the profectile velocities was $+0.2 \%$ except for shot 090 , where triggering errors necessitated the use of much lower precision timing data, resulting in a projectile velocity uncertainty of $\pm 6 \%$. The quartz arrival mirrors were illuminated with a Xenon lamp and observed with a TRW image converter streak camera writing on Royal $X \mathrm{fIlm}$ at $30 \mathrm{~mm} / \mu \mathrm{s}$. The streak records were calibrated using a modulated laser beam producing timing marks at $162 / 3$ ns intervals on the film. Additional details appear in Jackson and Ahrens [1979] and Jeanloz and Ahrens [1980].

All streak records were scanned with a microphotometer, and arrival mirror reflection cutoffs were used to compute the sample and buffer mirror transit times from linear or quadratic least squares fits to the photometer scans. Corrections were applied for projectile tilt and bowing and for nonlinear streak camera writing rate, as required. These effects are described in detail by Jackson and Ahrens [1979] and Jeanloz and Ahrens [1980]. Sample and buffer shock wave velocities could thus be determined to with in 1-2\%. Hug on lot and partial release state particle velocities, densities, and pressures were computed using the impedance matching technique and the Riemann integral approximation [Rice et al., 1958; Lyzenga and Ahrens, 1978; Jeanloz and Ahrens,1979]. Equation of state data for tantalun were taken from McQueen et al. [1970] and for fused quartz from Wackerle [1962] and Jackson and Ahrens [1979].

Three experiments were also carried out at low pressures in a single-stage $40-m$ propellant gun to study directional varlation of the Hugoniot elastic limit (HEL) of forsterite to compare with the extensive low-pressure shock-wave work of Syono et al. [1981a]. Raikes and Ahrens [1979] reported an HEL measurement of single-crystal forsterite shocked along the $c$ axis. In the present work, one sample of forsterite was shocked along the $b$ axis and two along the a axis. The elast $1 c$ precursor to the shock wave was detected using an inclined mirror mounted on top of the sample. Details of the technique are given by Ahrens et al. $[1968,1971]$ and Raikes and Ahrens [1979].

\section{Results and Discussion}

Table 1 lists the measured sample densities, projectile velocities, and sample and buffer mirror shock wave velocities, as well as the calculated Hugoniot and partial release states for the experiments with shock propagation along the forsterite a and $c$ axes (three shots for each direction). Flgure 1 shows sample shock wave velocity, $u_{s}$, versus sample particle velocity, $u_{0}$. Also included are data of Jackson and Ahrens ${ }^{2}$ [1979] for shock propagation along the $b$ axis, the singlecrystal forsterite measurements of Syono et al. [1981a] for propagation along all three axes, and dense polycrystalline (porosity < 1\%) forsterite data of McQueen [1968] and Marsh [1980] at low particle velocities. The data at particle velocities over $3.5 \mathrm{~km} / \mathrm{s}$ are well described by stralght lines with slopes greater than the straight line fitting the lower velocity data and are conven- 




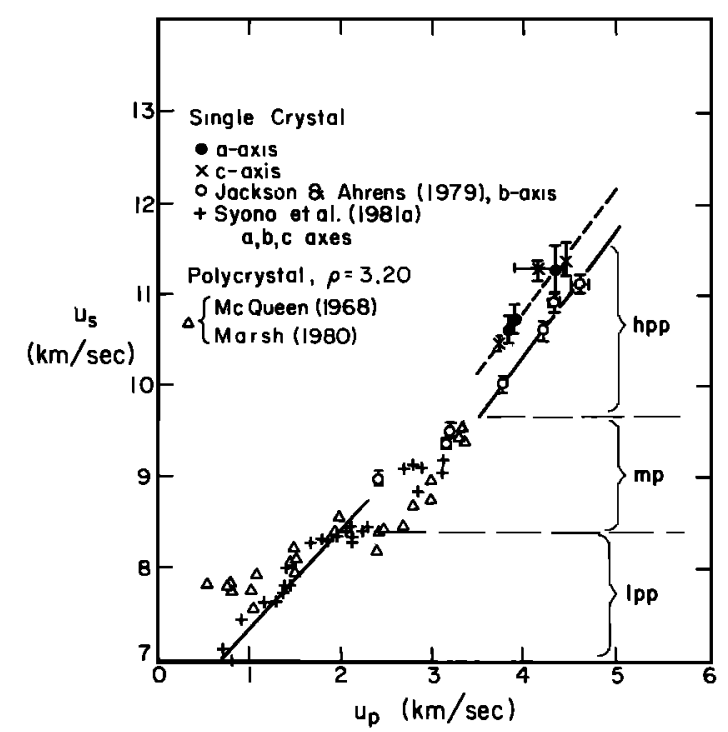

Fig. 1. Forsterite $u_{-}-u_{\text {data }}$ for single orystals shocked alang the $p_{\text {three orthorhombic axes }}$ and for dense polycrystals. Low-pressure phase (1pp), mixed-phase (mp), and high-pressure phase (hpp) regions are indicated.

tionally interpreted as representing a high-pressure phase. The a- and c-axis data are displaced to lower particle velocities relative to the baxis data of Jackson and Ahrens, although slopes of the two straight line segments are the same. A linear least squares flt to the b-axis data gives $u_{s}=4.87(+2.48)+1.37(+0.18) u$ with a correlation coefficient of $0 . \overline{97}$ ( 4 pbints), while the fit to the combined a- and c-axis data, onitting the uncertain datum at $u=4.20 \mathrm{~km} / \mathrm{s}$ (shot 090) is $u_{s}=5.60( \pm 1.22)+1.38( \pm 0.08) u_{p}$ with a correlation coefflcient of $0.99^{-}(5$ datg). The line at particle velocities below $2.0 \mathrm{~km} / \mathrm{s}$ is a linear least squares fit of Syono et al. [1981a] to their single-crystal data. There is no directional dependence evident in these previous data and, accordingly, the sample orientations are not given in the figure (Fig. 2 of Syono et al. distinguishes the three axes).

Figure 2 shows the calculated Hugonlot states for the present a- and c-axis experiments as well as the b-axis data of Jackson and Anrens [1979], the single crystal data of Syono et al. [1981a] and Paikes and Ahrens [1979], and the dense polycrystal data of McQueen[1968]. The curves are for $v$ isual convenience only. The $a-$ and c-axis data offset in Flgure 1 produces a displacement of the Hug on lot to lower densities relative to the $b$-axis Hugoniot. To insure that this difference between the $a-$ and $c-a \times i s$ and $b$-axis results was not the result of blas in reading the shock-wave records, the streak records for the b-axis experiments reported by Jackson and Ahrens were reanalyzed using the same methods as for the a- and $-c$ axis experiments. Our reanalysis of the $b$-axis records ylelded Hugonlot states in agreement with those determined by Jackson and Ahrens with in one standard error, except for the points at 98 and $122 \mathrm{GPa}$, which agreed with in two standard errors. Thus we conclude that at pressures above $100 \mathrm{GPa}$, sing le-crystal forsterite is most compressible along the $b$ axis, with lower, but nearly equal, 


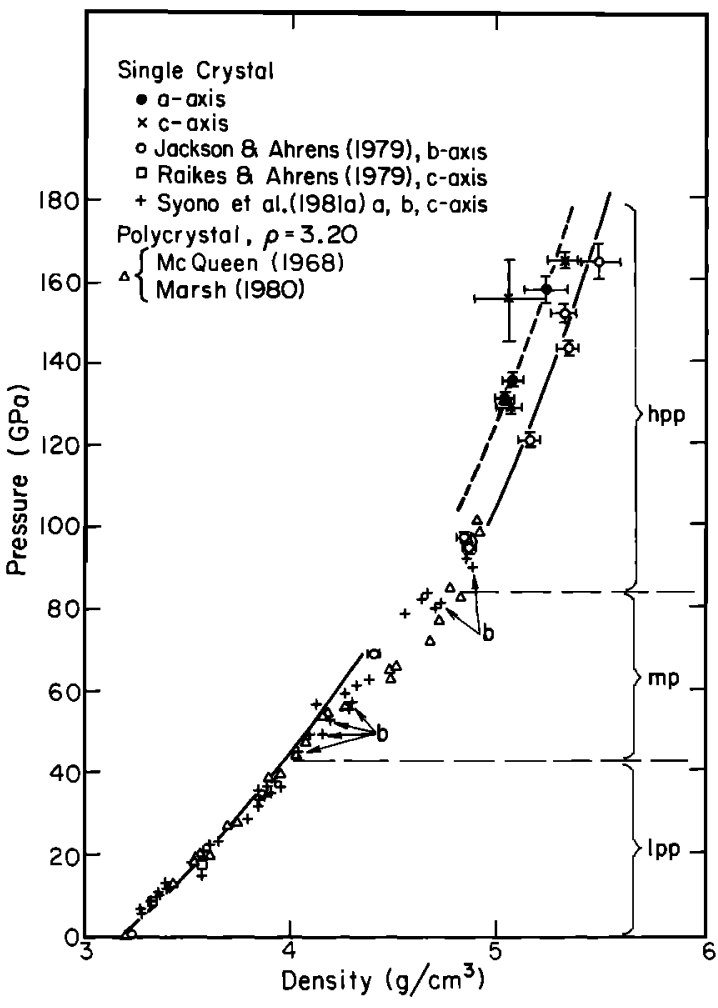

F1g. 2. Hugoniot states for single-orystal forsterite shocked along the three orthorhombic axes and for dense polycrystals in three regimes. The b-axis data of Syono et al.[1981a] are indicated. Greatest compressibilty for the mixed-phase and high-pressure regions occurs along the $b$ axis. Curves are for visual convenience only.

compressibilities for the a and $c$ axes. This disagrees with the crystallographic model of Jeanloz [1980] that predicts highest compressibility for the a axis.

Careful examination of the single-crystal forsterite data of Syono et al. [1981a] to pressures up to $92 \mathrm{GPa}$ provides marginal evidence of directional dependence in ag reement with our results. The b-axis data of Syono et al. are indicated in Figure 2 and, in general, lie at densities higher than those reached by the $a-$ and $c$-axis samples; there is no obvious distinction between the aand c-axis Hug oniot data. The estimated density error in the data $( \pm 18)$ is just under twice the width of the plotted crosses, so that the directional dependence is not obvious from their data alone, but taken with our high-pressure results, produce a consistent picture of greater b-axis compressibility above pressures of $50 \mathrm{GPa}$.

Directional dependence for dynamic properties has been observed earlier in single-crystal calcite, ilmentte, and sodium chloride. Ahrens and Gregson [1964] found that calcite is most compressible when shocked along the trigonal (z) axis to pressures of $25 \mathrm{GPa}$. Calculation of compressibility $\beta(i)$ along the $i$ axis from singlecrystal elastic constant data of Dandekar and Ruofe $[1968]$ gives $\beta(x)=\beta(y)=2.7 \times 10^{-3} \mathrm{GPa}^{-1}$ and $\beta(z)=3.2 \times 10^{-3} \mathrm{GPa}^{-1}$, in agreement with the shock observation. Thus, the relative compressibilities of the calcite axes persist across the three calcite phase transformations observed
In the dynamic experiments. KIng and Ahrens[1976] observed that single-crystal ilmentte shocked to $70 \mathrm{GPa}$ was most compressible along the trigonal axis, in agreement with static compression data of Liu et al. [1974] for a magnesian ilmenite. Additionally, shock-compression data for singlecrystal sodium chloride [Fritz et al., 1971] indicate that the pressure at which the B1-B2 displacive transition occurs under shock varies with shock propagation direction. We note that in calcite and 1lmenite, directional depend ence occurs throughout the whole pressure range of the experiments, while the forsterite data of Syono et al. [1981a] show no marked dependence on shock propagation direction from the Hugonlot elastic limit to the start of the mixed-phase region around 40 $\mathrm{GPa}$ and even beyond.

The present olivine observations represent the highest pressures at which directional depend ence of shock properties has been found. At pressures so far above the elastic limit of olivins, 6-13 $\mathrm{GPa}$ [Syono et al., 1981a], the hydrostatic approximation should be well satisfied and directional dependence would not be expected. One possible explantion could be sluggish reaction kinetics along the $a$ and $c$ axes compared to the $b$ exis, although again the high pressures make this rather unlikely, and our a- and o-axis data show no evidence for compression approaching the b-axis values, even at $160 \mathrm{GPa}$. Additional recovery studies similar to that of syono et al. [1981b] may Indicate whether or not the amount of transformation products at a given pressure is direction dependent.

The partial relese paths for the a-axis shots (not plotted in Figure 2 for clarity) are steep, and similar to those found by Jackson and Ahrens for the $b$ axis, implying persistence of the highpressure phase as the samples unload. The c-axis release paths, on the other hand, are much shallower than for the other axes, suggesting more rapid reversion of the high-pressure phase as the samples begin to unload. Thus it seems that there is different behavior upon release from simtlar Hugonlot states, depending on the axts involved.

We now compare our high-pressure Hugonlot data for olivine with theoretical Hugonlots for mixedoxide and $\mathrm{MgO}+\mathrm{MgSiO}_{3}(\mathrm{pv})$ as semblages calculated from ultrasonic, static compression, and Brillouin scattering data. Table 2 lists the equation of state data used for $\mathrm{MgO}, \mathrm{SIO}_{2}$ (stishovite), and

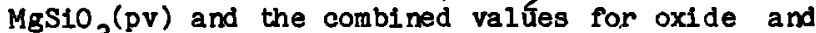
perovskite assemblages. The $K$ and $\partial K / \partial P$ data for $\mathrm{MgO}$ are the values of Spetzler [1970] as well as recent shock wave and ultrasonic work of Vassiliou and Ahrens [1981] and Jackson and Niesler [1982]. The zero-pressure Gruneisen parameter, $\gamma$, is that of Anderson and Andreatch [1966]. We assume that the Gruneisen parameter varies with volume as $\gamma / \gamma=(\rho / \rho)^{n}$ and take $n=1.5$, with a large uncertainly (see Davies [1974] for typical values of $n$ for close-packed oxldes). The $K$ value for stishovite is the average of the telragonal polyorystalline Hashin-Shtrikman bounds [Watt and Peselnick, 1980] calculated from the Brillouin scattering single-crystal elasticity data of Weldner et al. [1982]. Weldner et al. concluded that their Brillouin data, combined with isothermal hydrostatic compression results, suggest that $\partial K / \partial P$ for stishovite is lower than for other rutile-structure oxides. Ultrasonic values of $\partial \mathrm{K} / \partial \mathrm{P}$ 
TABLE 2. Forsterite Equation of State Parameters for Theoretical High-Pressure Phase Hugoniots

\begin{tabular}{|c|c|c|c|c|c|}
\hline & Mgo & $\begin{array}{c}\mathrm{StO}_{2} \\
\text { (stish.) }\end{array}$ & $\begin{array}{l}\mathrm{MgSiO}_{3} \\
\text { (perov?) }\end{array}$ & $\begin{array}{r}2 \mathrm{MgO} \\
+\mathrm{SiO}_{2}\end{array}$ & $\begin{array}{c}\mathrm{MgO} \\
+\mathrm{MgSIO}_{3}\end{array}$ \\
\hline${\stackrel{\mathrm{K}}{0}, \mathrm{~g} / \mathrm{cm}^{3}}_{\mathrm{GPa}}$ & $\begin{array}{l}3.584 \\
163 .\end{array}$ & $\begin{array}{l}4.29 \\
316 .\end{array}$ & $\begin{array}{l}4.10 \\
260 .\end{array}$ & $21 \frac{3.86}{1}$ & $\begin{array}{r}3.94 \\
224\end{array}$ \\
\hline $\begin{array}{l}\partial R / \partial P, \\
\quad \text { dimensionless }\end{array}$ & $\begin{array}{r}4.1 \\
( \pm 0.2)\end{array}$ & $\begin{array}{c}( \pm 1 .) \\
4 . \\
( \pm 1 .)\end{array}$ & $\begin{array}{c}-4 . \\
( \pm 1 .)\end{array}$ & $\begin{array}{c}4.1 \\
( \pm 0.5)\end{array}$ & $\begin{array}{r}4.0 \\
(+0.7)\end{array}$ \\
\hline$\gamma_{o}^{\prime}{ }_{\text {dimensionless }}$ & -1.54 & $\begin{array}{c}-1.5 \\
(+0.2)\end{array}$ & $\begin{array}{c}-1.0 \\
( \pm 0.5)\end{array}$ & $\begin{array}{c}1.0 \\
(+0.5)\end{array}$ & $\begin{array}{l}1.0 \\
(+0.5)\end{array}$ \\
\hline n, dimensionless & 1.5 & 1.5 & 1.5 & $\begin{array}{c}1.5 \\
(+0.5)\end{array}$ & $\begin{array}{r}1.5 \\
(+0.5)\end{array}$ \\
\hline $\mathrm{E}_{\mathrm{tr}}, \mathrm{kJ} / \mathrm{g}$ & - & - & - & $\begin{array}{c}1.0 \\
(+0.5)\end{array}$ & $\begin{array}{r}1.0 \\
(+0.5)\end{array}$ \\
\hline
\end{tabular}

for $\mathrm{SnO}_{2}, \mathrm{GeO}_{2}$ and $\mathrm{THO}_{2}$ are $5.13,6.15$ and 6.80 , respectively [Chang and $G$ rah am, 1975]. According$1 y$, we ælopt st1shovite $\partial K / \partial D$ as $4 \pm 1$ (see also Bass et al [1981]). The values of $p, k$, and $\partial R / \partial P$ for $\mathrm{MgSiO}_{3}(\mathrm{pv})$ are those due to Yagi et al. [1979a, b]. We calculate zero-pressure properties for oxide and perovskite as semblages from the values for the separate components. The elastic moduli are averaged using the Voigt-Reuss-Hill two-phase average; Hashin-Shtrikman bounds cannot be used because they require the shear moduli of the phases. The oxide and perovskite zero-pressure Granelsen parameter is found from shook-wave

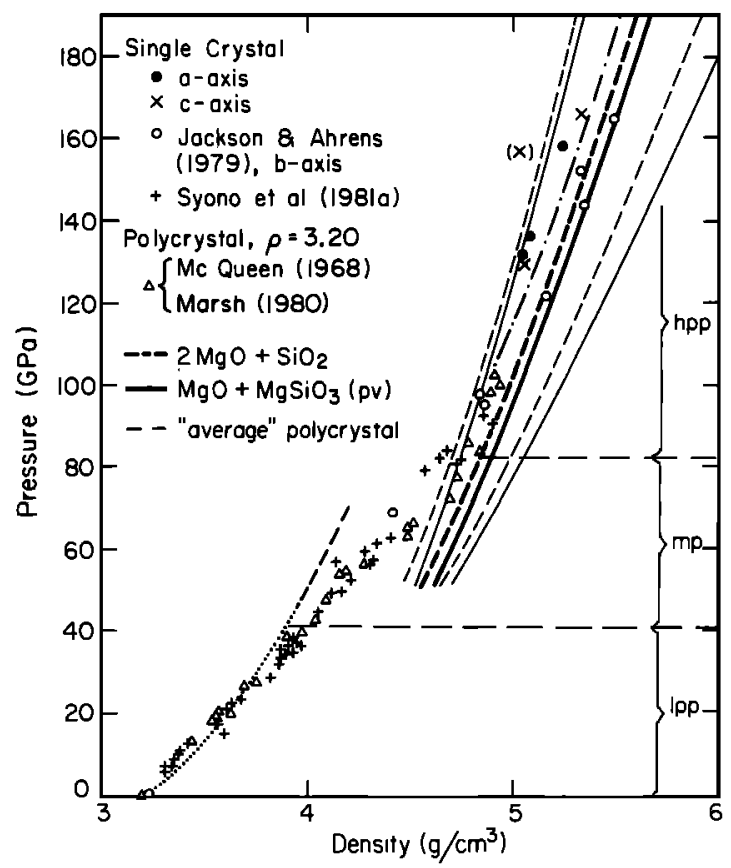

F1g. 3. Calculated Hugoniots for forsterite compared with observed data. In the high-pressure reglme, dashed curves are for mixed oxides, solid curves are for a perovskite-structure assemblage. Heavy curves were calculated using the preferred values in Table 2; Iight curves Include combined uncertainties in the equation of state parameters. The "average" curve was cal aul ated using equation (1). measurements on slightly porous forsterite (R. $G$. McQueen, personal communication, 1981) to which we assign a large uncertainty. We use the estimate of Jackson and Ahrens [1979] for the trans1tion energy, $E_{t r}$.

We use third-order finite strain theory and relate isentropes and Hugoniots through the Grineisen parameter; the complete equations appear In Jackson and Ahrens [1979]. The calculated Hugoniots are shown in Figure 3. The dotted curve at low pressures is the theoretical Hugoniot derived from the ultrasonic forsterite data of Graham and Barsch [1969] and Kumazawa and Anderson [1969], collected in Table 3 of Jackson and Ahrens [1979]. In the high-pressure regime, the dashed arves are theoretical Hugoniots for mixed oxides; the solid arves are for an $\mathrm{MgO}+\mathrm{MgSiO}_{3}$ (pv) assemblage. The heavy curves were calculated from the preferred equation of state parameters in Table 2; the light curves 1nclude combined uncertainties in all the parameters.

Both the mixed-oxide and the perovskite assemblage preferred high-pressure Hugonlots match the b-axis data of Jackson and Ahrens. In their amalysis, Jackson and Ahrens concluded that a mixedoxide Hugonlot did not lead to sufflciently high densities to account for their data. This was a result of the high values of stishovite $\partial K / \partial P$ $(=6)$ and $\gamma(=1.5)$ used in their amlysis.

Jackson and Ahrens treated two possible values for $\mathrm{MgSHO}_{3}(\mathrm{pv}) \mathrm{K}$ : an estimate of Llebermann et al. [1977] of $250^{\circ} 30 \mathrm{GPa}$ based on elasticity systematios and a preliminary statio compression value of Yagi et al. [1978] of $286 \pm 30 \mathrm{GPa}$. These data led to values of $\mathrm{K}$ for $\mathrm{MgO}+\mathrm{MgStO}_{3}(\mathrm{pv})$ of 219 and $239+20 \mathrm{GPa}$ respectively, compared 3 to the value of $224+12 \mathrm{GPa}$ used here from the refined determination of Yagi et al. [1979b]. The present pv as semblage parameters (Table 2), with lower $\partial K / \partial P$ and $\gamma$ than used by Jackson and Ahrens lead to a prefferred hpp Hugon 1 ot about $0.1 \mathrm{~g} / \mathrm{cm}^{3}$ denser than the Jackson and Ahrens Hugon lot with a $\mathrm{pv}_{3}$ as semblage $\mathrm{K}_{0}$ of $219 \mathrm{GPa}$ and about 0.05 $\mathrm{g} / \mathrm{cm}^{3}$ denser than our mixed-oxide Hugon lot.

The spread in ipp Hugoniot values when all the uncertalnties in the equation of state parameters are included is large, even with recent refinements in stishovite and $\mathrm{MgSiO}_{3}$ (pv) data. For a given Hugoniot pressure, 50 to $75 \%$ of the overall density spread is attributable to the uncertain- 
ties in $K$ and $\partial K / \partial P$. Obviously, further refinement of these parameters, especially $R / P$, is of great interest for more rigorously comparing our hpp shock-wave data with extrapolations of static compression, ultrasonic, and Brillouin scattering data.

Given uncertainties in the EOS data, we conclude that, at present, the two computed forsterite Hugoniots are essentially Identical, as noted earlier by Anderson [1977] and Yagi et al. [1978]. The preferred curves are in excellent agreement with the b-axis data of Jackson and Ahrens. The present a- and c-axis data are 0.15$0.20 \mathrm{~g} / \mathrm{cm}^{3}$ less dense than the theoretical Hugoniots, but still within the range of uncertainty, so neither mixed-oxide nor perovskite-structure assemblages can be excluded as explarations for the new data. We note that there is no need to Invoke phase changes to forms denser than the perovskite structure to explain the forsterite data. This conclusion is supported by shock-wave work on enstatite [J. P. Watt and T. J. Ahrens, manuscript in preparation, 1983].

We have fltted Hugoniots through the a- and c-axis data and data at pressures above $90 \mathrm{GPa}$ of Syono et al.[1981a], McQueen [1968], Marsh [1980] and Jackson and Ahrens [1979], excluding the four highest b-axis data, to estinate $K$ and $\partial K / \partial P$ values required by these lower compressibility data. With $\gamma, n$, and $E_{\text {fr }}$ fixed at the preferred values in Table 2, we flnd that $K$ and $\partial K / \partial P$ are $207 \mathrm{GPa}$ and 5.2 , respectively, for oxides $(\rho=$ $3.86 \mathrm{~g} / \mathrm{cm}^{3}$ ) and $253 \mathrm{GPa}$ and 4.6 , respectively, for a $p v$ as semblage $\left(\rho_{0}=3.94 \mathrm{~g} / \mathrm{cm}^{3}\right)$ for the $10 \mathrm{da}-$ ta points used in the fit. These values are by no means un reasonable. On the other hand, assuming that all the high-pressure phase equation of state parameters, except zero-pressure density, for the a- and c-axis samples are the same as the preferred values for a perovskite-structure assemblage (Table 2), we can find $\rho_{0}$ of the highpressure phase needed to satisfy the a- and caxis data. We calculate a $\rho_{0} g^{\mathrm{f}} 3.77 \mathrm{~g} / \mathrm{cm}^{3}$ compared to the value of $3.94 \mathrm{~g} / \mathrm{am}^{3}$ need ed to satisfy the $b$ axis data and calculated from static compression results. Thus the "average" zeropressure density of the high-pressure phase of shock-loaded forsterite is between 3.80 and 3.90 $\mathrm{g} / \mathrm{cm}^{3}$ and is less than one would expect for an $\mathrm{MgO}+\mathrm{MgSiO}_{\mathrm{g}} \mathrm{pv}$ ) as semblage. The uncertainties in the equation of state parameters, however, do not necessarily require such a lowered density.

We can estimate a high-pressure phase Hugoniot of polycrystalline forsterite from the $a-, b-$, and c-axis data by using the following simple approach. If we consider polycrystalline forsterite as a random mixture of single crystals with the three axes represented in statistically equal amounts, the average Hugoniot of the mixture can be computed from the mass fraction weighted Hugoniot densities of the three "components" [Ahrens et al., 1977]. This method has been shown to reproduce the Hugoniots of rocks whose mineral components have been well characterlzed under shock, for example, Westerly granite. Since the a- and c-axis Hugoniot densities are virtually equal, we can write an "average" polycrystalline density $\langle\rho\rangle$ at a given pressure as

$$
\langle p\rangle=3[2 / \rho(a, c)+1 / p(b)]^{-1}
$$

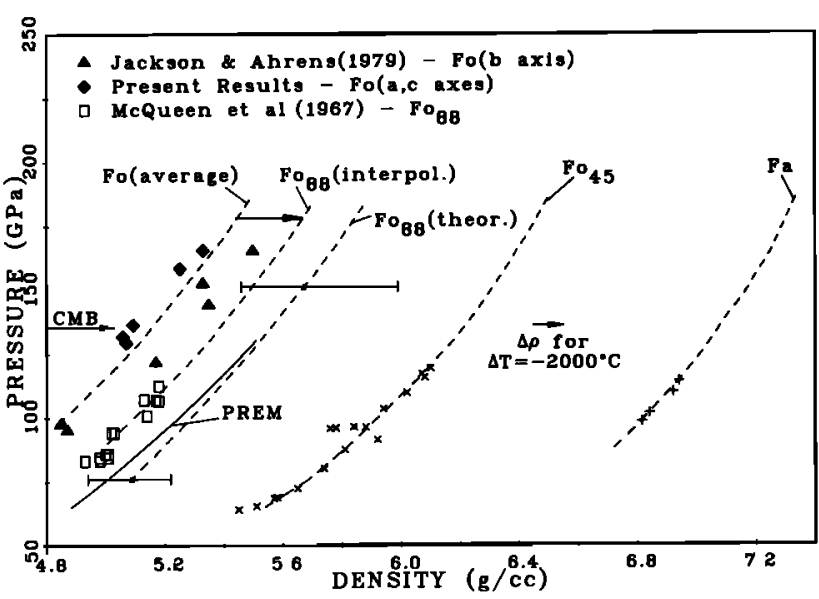

Fig. 4. Summary of shock compression data for olivines. Fo ${ }_{88}$ curve is a linear interpolation between the "average" Fo, curve and Fa. Data for $\mathrm{FO}_{45}$ and $\mathrm{Fa}$ are from 1 feQueen and Marsh[1 966], MCQueen et al. [1967], and Marsh [1980]. Also shown is a theoretical Hugoniot for $\mathrm{FO}_{88}$ calculated from third-order finite strain and 88 trasonic and static compression equation of state parameters. The Parametric Reference Earth Model (PREM) is given to the core-mantle boundary (CMB). The line labelied $\Delta \rho$ represents the density increase for a reduction in temperature of $2000 \mathrm{~K}$ from the CMB Hugoniot to lower mantle temperatures.

where $\rho(x)$ is the Hugoniot density of the $x$ axis. We plot our calculated $\langle\rho\rangle$ in Figure 3 and conclude that polyorystalline forsterite should, on average, shock load to densities lower than those of the preferred theoretical Hugoniots. Note that the dense polyorystal data of McQueen [1968] and Marsh [1980] at pressures around $100 \mathrm{GPa}$ are consistent with this conclusion, thus giving confidence in Hugoniot data obtained from dense polycrystals. We emphasize that this averaging method is simplistic, but given the errors in the experimental data, more rigorous averaging treatments are not warranted.

We estimate the bulk modulus and its pressure derivative of the high-pressure phase of forsterite by combining our "average" polyorystalline Hugoniot with dense polycrystal data of McQueen [1968] and Marsh[1980] at pressures above $90 \mathrm{GPa}$. Reeping $\mathrm{n}, \quad$, and $\mathrm{E}_{\text {tr }}$ fixed at their values in Table 2, we find that varying the zero-pressure density of the high-pressure phase from 3.6 to $3.8 \mathrm{~g} / \mathrm{cm}^{3}$, the bulk modulus increases from 141 to $217 \mathrm{GPa}$, and its flrst pressure derivative decreases from 4.9 to 4.0 .

We now compare the forsterite single-crystal results with $\mathrm{P}-\rho$ values for the lower mantle derived from inversion of normal mode and seismic travel time data. In Figure 4, we plot the Hugoniot data for single-crystal forsterite, Fo, for the three or thorhombic axes. We also include data of McQueen and Marsh [1966] and Marsh [1980] for fayalite, Fa, (Rockport, Massachusetts, $\rho=4.28$, compared to 4.38 for stoichiometric fayalite), Fo (dunite, Mooihoek Mine, Transvaal [McQueen et a1., 1967]), and $\mathrm{Fa}_{12}$ (dunite, Twin Sisters Peaks, Washington [McQueen et al., 1967]). Note that Jackson and Ahrens [1979] incorrectly take Twin 
Sisters dunite composition as $\mathrm{Fo}_{02}$ rather than $\mathrm{Fo}_{88}$ [Birch, 1960]. We plot pressure2 vs. density for the Preliminary Reference Earth Model (PREM) [Dziewonski and Anderson, 1981] in the lower mantle to the core-mantle boundary (CMB).

We calculate Hugoniots for $\mathrm{FO}_{88}$ by linear interpolation between the Fo 10 and $\mathrm{Fa}$ data in $\mathrm{Fig}$ ure 4 to compare with both Twin Sisters dunite and the lower mantle. For $\mathrm{Fo},{ }_{100}$, we use our "averagen Fo 10 Hugoniot. The striking linearity of shock properties of olivines with iron content is apparent from the fact that interpolation between the forsterite single-crystal data and the Fo data ylelds virtually the same Fo Hugoniot ( 45 within $0.01 \mathrm{~g} / \mathrm{cm}^{3}$ ) as does interpolation between $\mathrm{Fo}$ and $\mathrm{Fa}$. The interpolated $\mathrm{Fo}$. Hugoniot is in excellent agreement with the Twin sisters dunite data. If the a- and c-axis Fo 190 data and the baxis Fo 100 data are used separately, the interpolated $\mathrm{FO} 8 \mathrm{~g}$ curves closely bracket the Twin Sisters dunite data. Note that interpolation using only the b-axis data overestimates Twin sisters densities. The Twin Sisters dunite data have previously not been well fit by "systematics" [see Jackson and Ahrens, 1979].

We include in Figure 4 a theoretical Hugoniot for $\mathrm{FO}_{88}$ calculated from the preferred EOS parameters for a perovskite-structure assemblage. The error bars include the combined uncertainties in $K$ and $\partial K / \partial P$. The theoretical Hug onlot ylelds $h$ igher densities than are found experimentaliy, a lthough the observed data are marginally compa$t$ tble with the range of theoretical densities. More static compression studies of perovskitestructure silicates, particularly investigations of $K$ and $\partial K / \partial P$, are needed to determine whether the apparent discrepancy between computed and observed ollvine thug on lots is real.

The present results do not suggest a need for "post-perovskite" phases of olivines as proposed by Jean loz and Ahrens [1977] and Jackson and Ahrens [1979]. Indeed, they offer only marginal ev1dence for formation of perovskite-structure highpressure products.

Finally, we compare experimental results for shook-compressed olivines with the lower mantle density of seismic earth model PRRM. We note that temperatures reached in shock-wave experiments at pressures comparable to lower mantle pressures are higher than estimated lower mantle temperatures. For example, Stacey [1977] calculated a temperature of $3157^{\circ} \mathrm{K}$ at the core-mantle boundary $(P=135 \mathrm{GPa})$, Brown and Shankland [1981] found $a$ value of $2449^{\circ} \mathrm{R}$ for an ad labatic mantle; a superadiabatic contribution estimated at $200 \mathrm{~K}$ would ralse the CMB temperature to $2650^{\circ} \mathrm{K}$. Lyzenga and Ahrens [1980] measured shook temperature in three forsterite single crystals shocked between 150 and $180 \mathrm{GPa}$ and combining their data and the forsterite hug on lot temperature calculations of Ahrens et al- [1969], found shock temperatures of $3800 \pm 750^{\circ} \mathrm{K}$ at $135 \mathrm{GPa}$. Thus shock temperatures at $135 \mathrm{GPa}$ (the base of the mantle) are $400-1900 \mathrm{~K}$ higher than those estimated in the Earth. The shock densities are consequently lower than would occur in the Earth. Correcting Hug on lot densities for this temerature effect would increase 3 the measured densities by no more than $0.10 \mathrm{~g} / \mathrm{cm}^{3}$ for a difference of $2000^{\mathrm{C}} \mathrm{K}$.

Taking this maximum density correction into account, we find that PREM and our interpolated $\mathrm{Fo}_{88}$ density curves are compatible. In fact, oli$v$ ine compositions of as low as $\mathrm{Fo}_{80}$ are permitted by the a- and c-axis Hug oniot data, assuming minImum values for ollvine shock temperatures, and compositions as $h 1 \mathrm{gh}$ as $\mathrm{Fo}_{89}$, from the $\mathrm{b}-\mathrm{axis}$ data and $\operatorname{maximum}$ shock temperatures. These values are lower than Liu's [1977], Watt and O'Connell's [1978], and Watt and Ahrens' [1982] Mg mole fractions of $0.90-0.95$ in perovskite-structure olivine and pyroxene lower mantles. These studies were based on static compression data for $p v$ and, as can be seen in Figure 4, lead to higher calculated lower mantle densities and thus higher $M$ mole fractions than observed in the shock-wave experiments. If we use the preferred theoretical $\mathrm{FO}_{88}$ curve and the measured $\mathrm{FO}_{45}$ and $\mathrm{Fa}$ data, we find that need a composition between Fo and Fo 96 , depending on the size of the temperature correction, to match PREM densities.

Thus, results of shock-wave compression experiments on olivines suggest that the lower mantle has an iron content similar to the upper mantle, where $\mathrm{M}_{\mathrm{g}}$ mole fractions range from 0.85 to 0.90 , or the lower mantle may be enriched in iron by up to 0.1 mole fraction. This is in contrast to the conclusion of similar, or depleted, lower mantle iron contents reached from consideration of statio compression data on olivines and pyroxenes. Obviously, better precision high-pressure studies, especially ones that address thermal properties, of olivines are necessary to resolve this discrepancy.

Table 3 presents the results of the Hug on $10 t$ elastic limit experiments. To calculate the elastic state, we use the free-surface approximation, $u_{p}=u_{f s} / 2$, where $u_{f s}$ is the sample free surface velocify determined from reflections from the inclined mirror on top of the sample [Rice et al., 1958]. We 1gnore interactions among the various waves in the samples; the error in so doing is sma 11 [Ra1kes and Ahrens, 1979]. We also Include for comparison the caxis datum of Ralkes and Ahrens [1979] and sumaries of the data of syono et al. [1981a]. In the latter case, we give averages for elastio velocities and elastic states with the number of measurements averaged indicated. In this case, the stated uncertainty is the largest deviation of the individual data points from the calculated average.

The present results are in good agreement with the data of syono et al. We do not compare deformational states, since these depend on projectile veloolty. Elastic states should, however, be comparable. The fiugon tot elastic limits increase for loading along the $a, c$ and $b$ axes, in that order. Elastic (compressional) velocities determined from the shock wave experiments ag ree with those measured ultrasonically [Graham and Barsch, 1969; Kumazawa and Anderson, 1969]. Ultrasonic veloc1ties are $10.10,7.88$, and $8.55 \mathrm{~km} / \mathrm{sec}$ for propagation along the $a, b$, and $c$ axes, respectively.

We find more complex behavior at low pressures than has been prevlously reported for shook loading along the a axis. Our b-axis streak record is very similar to that observed by Ralkes and Ahrens [1979] for loading al ang the $c$ axis, an elastic shook followed by a single deformational shock wave. Flgure 5 shows static and streak records for loading along the a axis (shot 515). The 


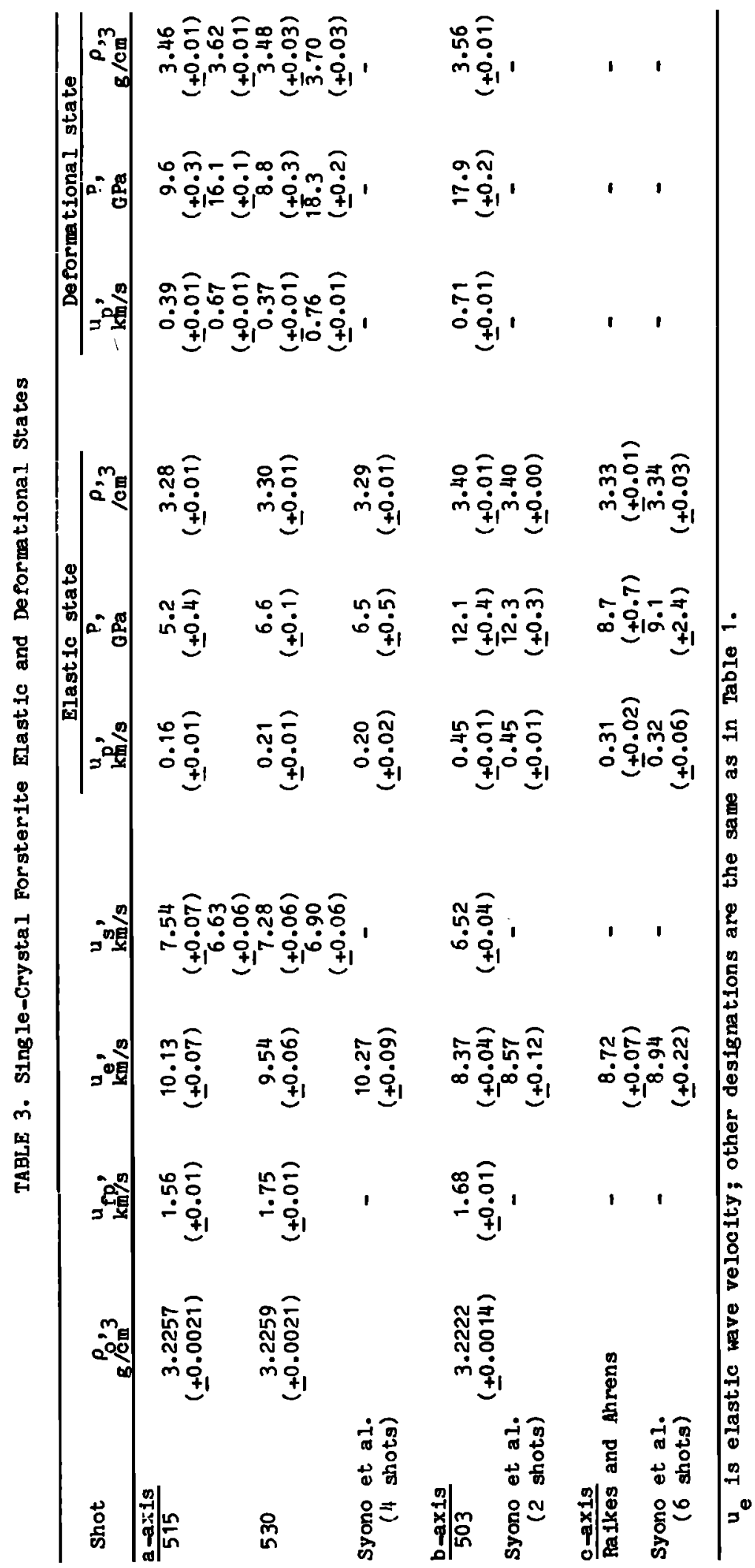


inclined mirror image cannot be explained by an elastic shock followed by a single deformational shock; instead, we require three distinct shocks to accommodate the two breaks in the inclined mirror inage. Moreover, three shock fronts are clearly discemible on the two flat arrival mirrors on the upper specimen surface. A similar complex structure was observed when the a-axis experiment was repeated (shot 530). Both shock states are included in Table 3. The elastic shock state, of amplitude $5.9+0.7 \mathrm{GPa}$, is followed by a second shock of $9.2+0 . \overline{4} \mathrm{GPa}$ amplitude. The third shock amplitude was $\overline{17.1}+1.1 \mathrm{GPa}$. Syono et al. do not describe such a structure in their four aaxis experiments, onssibly because their measurements were made at higher projectile velocities $(2.0-3.8 \mathrm{~km} / \mathrm{sec})$ than the $1.6-1.8 \mathrm{~km} / \mathrm{s}$ range of the present experiments. Figure 1 of Syono et al. [1981a], a streak record for an a-axis experiment appears to exhibit some curvature in the region between labels $t$, and $t$, and thus may be similar to that in Figure 20 of Ahrens and Gregson [1964] for Solenhofen Iimestone and attributed by them to nonequilibriur states between the HEL and the final, stable shock state.

Another explamation could be that the second, intermediate shock front represents the forsterite $\alpha \rightarrow \beta$ or $\gamma$ transition that has not been previously observed under shock lading. Calculation of temperature on the forsterite Hugoniot at 10 $\mathrm{GPa}$ using a Gruneisen parameter of 1.13 [Graham and Barsch, 1969; Kumazawa and Anderson, 1969] gives a value of no more than $50^{\circ} \mathrm{C}$. Extrapolation of the static compression $\alpha \rightarrow \beta$ phase boundary of Suito [1977] to $50^{\circ} \mathrm{C}$ yields a transition pressure of $11 \mathrm{GPa}$, while the phase boundary of I to et al.[1971] extrapolates to $6 \mathrm{GPa}$. Extrapolation of Suito's [1977] $\beta \rightarrow \gamma$ phase boundary to $50^{\circ} \mathrm{C}$ produces a transition pressure of $11.8 \mathrm{GPa}$. These estimates compare to a pressure of $9-10 \mathrm{GPa}$ found for the second shock in our experiments. Thus the observed pressure is compatible with that expect-

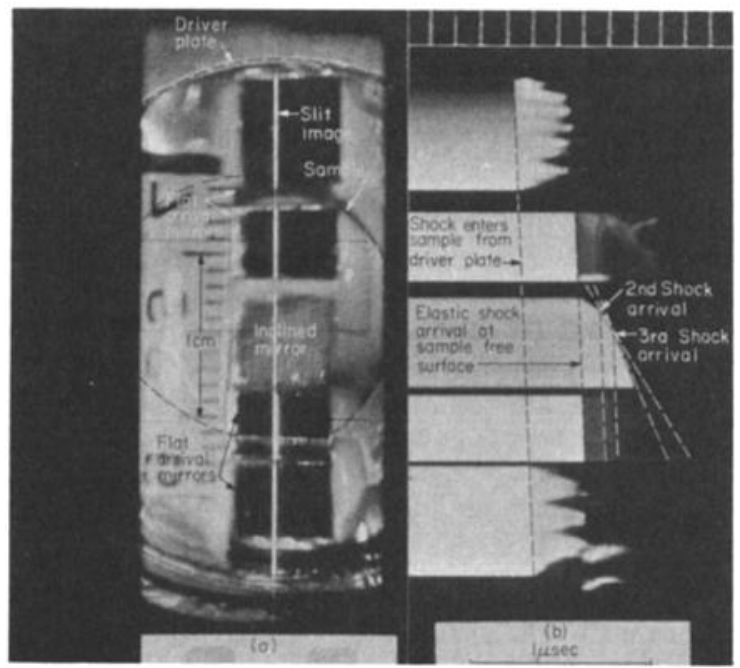

Fig. 5. Static and dynamic streak images for shot 515 upon shock compression to $16 \mathrm{GPa}$ alang the a axis of single-crystal forsterite. (a) Static image as seen through streak camera. (b) Streak image showing three-wave structure recorded by inclined mirror and flat arrival mirrors.

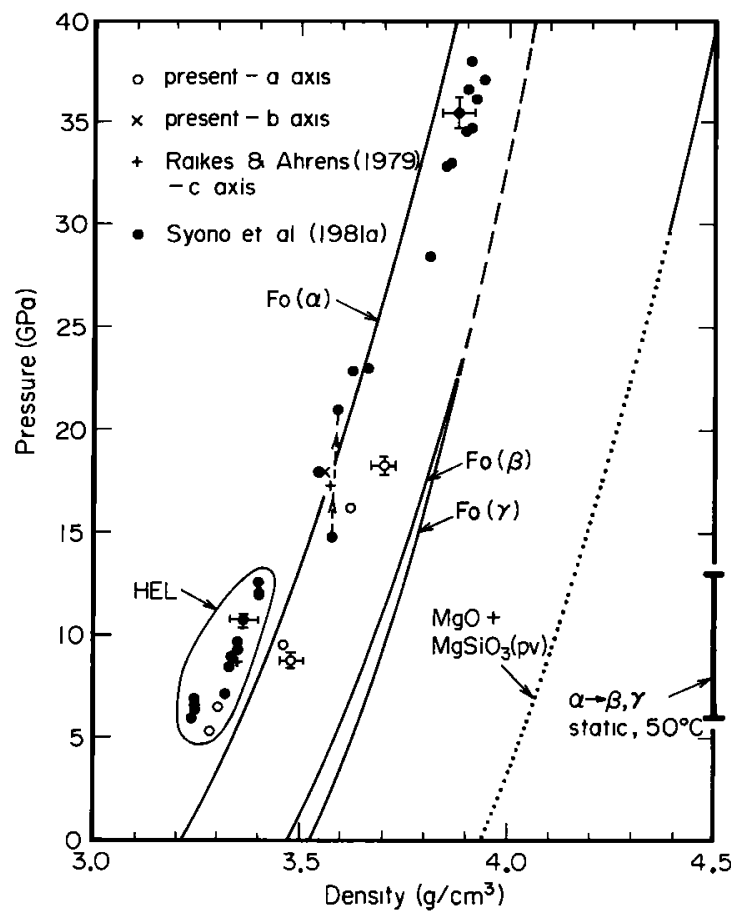

Fig. 6. Experimental Hugoniot data for singlecrystal forsterite for pressures up to $40 \mathrm{GPa}$ and computed Hugoniots for the $\alpha, \beta$, and $\gamma$ phases of forsierite and for a perovskite-structure highpressure assemblage. The pressure range at which the $\alpha \rightarrow \beta$ or $\gamma$ transformation could occur at static conditions (extrapolated to $50-100^{\circ} \mathrm{C}$ ) is shown. HEL denotes the Hugoniot elastic limit.

ed for the $\alpha \rightarrow \beta$ or $\gamma$ transformation occurring at low temperatures.

In Figure 6 we plot the present data for the a- and b-axis shots, the c-axis data of Raikes and Ahrens [1979], and that of syono et al. [1981a] at Hugonlot pressures below $40 \mathrm{GPa}$. We include typical errors for the Syono et al. data. Also shown are theoretical Hugoniots calculated for $\alpha, \beta$, and $\gamma$ phases of forsterite from the equation of state data collected by Jeanloz and Thompson [1983]. The data of Syono et al. and the $b$ and $c$ axis data are in excellent agreement with the $F o(\alpha)$ Hug on 1ot for pressures to $30 \mathrm{GPa}$; for $h$ igher pressures, the measured points are displaced to higher densities. The Syono et al. datum at $15 \mathrm{GPa}$, below the theoretical Hug oniot, was calculated using the free-surface approximation; the dashed line joins this point to the corresponding point at $21 \mathrm{GPa}$ computed by the impedance matching method. Thus the reliability of the free-surface approximation point is questionable. In all other cases where syono et al. [1981a] analyzed their data by using both techniques, the calculated Hug on lot pressures below $40 \mathrm{GPa}$ ag reed with in $1.5 \mathrm{GPa}$ or less. Our a-axis Hug on iot data between 9 and $10 \mathrm{GPa}$ are shifted to higher densities relative to the Fo $(\alpha)$ theoretical fug oniot, as are the data at 16 and $18 \mathrm{GPa}$ arising from the third shock. Thus the mixedphase region for loading along the a axis begins at pressures 10-15 GPa lower than for the $b$ and $c$ axes. This strongly suggests that a phase transition is occurring in the forsterite samples 
shocked along the a axis. It is unlikely that this represents the onset of the $\mathrm{MgO}+\mathrm{MgSIO}_{3}(\mathrm{pv})$ transition that ocurs at about $27 \mathrm{GPa}$ under static conditions, extrapolated to $50^{\circ} \mathrm{C}$ from data of Ito and Yamada [1982], and we conclude that our a-axis data may represent the $\alpha \rightarrow \beta$ or $\gamma$ transition in forsterite. The density increase at 9 $\mathrm{GPa}$ is 1-2\% compared to the 6-8\% increase needed for complete transformation to the $\beta$ or $\gamma$ form. We note that because of the very similar $\beta$ and $\gamma$ Hugoniots, it will likely not be possible to distinguish between the two phases in shock experiments if our a-axis observation is confirmed to represent a phase transformation.

Two possible problems with this explanation are the question of whether the transition kinetics are such as to allow the transformation to occur over the short duration of shock loading and the fact that many transformations that have been observed under shock require considerable pressure overdriving compared to static experiments. Moreover, the hypothesis that the onset of a shock-induced phase change occurs at about 9 GPa implies that the Hug on iot represents an equilibrium phase assemblage more closely than has heretofore been assumed. Poirier [1981] modelled the $\alpha \rightarrow \beta$ transition in terms of propagating partial dislocations, and his results would seem to indicate that the transition could not occur at the conditions of the shock experiments. Obvious$l y$, this new observation of what appears to be a transition shock wave in forsterite compressed along the a axis merits further investigation.

\section{Conclusions}

We report dynamic compression results for single-crystal forsterite shocked along the $a$ and c axes for comparison with b-axis data of Jackson and Ahrens [1979]. Our a- and c-axds results are displaced to lower particle velocity in $u_{-u}$ space relative to the data for the $b$ axis. The $a$ p and c-axis data form a single straight line parallel to the straight line for the b-axis values. In $P-\rho$ space, the a- and c-axis velocity offset leads to a displacement of the Hugoniot to lower densities compared to the b-axis Hugoniot indicating that single-crystal forsterite is most compressible along the $b$ axis. This observation disagrees with the prediction of maximum compression along the a axis from the crystal lographicallybased model of Jeanloz [1980] that does not invoke phase transitions to account for the highpressure dynamic behavior of forsterite.

These data represent the highest pressures for which directional dependence of dynamic behavior has been found. Directional dependence has been reported previously for much lower pressures for single-crystal calcite, ilmenite and sodium chloride. The extensive single-crystal results of Syono et al. [1981a] to pressures of $92 \mathrm{GPa}$ exhibit slightly higher densities for compression of the b axis in agreement with the present results, although estimated errors in the lower pressure data do not allow an unambiguous conclusion to be reached when the data are examined independently of the present data.

We have compared our Hugoniot data with theoretical Hugoniots for mixed-oxide and perovskitestructure assemblages of forsterite constructed using recent static compression, ultrasonic, and
Brillouin scattering data. We find that the highpressure Hugoniots of mixed-oxide and perovskitestructure assemblages are nearly Indistinguishable and are in excellent agreement with the data of Jackson and Ahrens [1979] for the b axis. This we do not require transformation to structures denser than oxides or perovskites to explain the shock-wave data. The 2 - and $c$ - axis data are less dens? than the calculated Hugonlots by $0.15-0.20$ $\mathrm{g} / \mathrm{cm}^{3}$, but lie within the range of Hugoniots produced by the combined uncertainties in the equation of state data. From 50 to $70 \%$ of the overall uncertainty is caused by the uncertainty in $K$ and $\partial K / \partial P$, so that refinement of these values is of great interest, especially for $\mathrm{MgSiO}_{3}(\mathrm{pv})$.

Least squares fIts to the data for the a and $c$ axes with $\rho$ fixed at values appropriate for mixed-oxide and perovskite assemblages yield $k$ and $\partial \mathrm{K} / \partial \mathrm{P}$ values of $207 \mathrm{GPa}$ and 5.2 , respective? $1 \mathrm{y}$, for oxides and $253 \mathrm{GPa}$ and 4.6 respectively, for a pv assemblage. We have estimated a zeropressure density of the high-pressure phase of the $\mathrm{z}-$ and c-axis shock-loaded forsterite of 3.77 $\mathrm{g} / \mathrm{cm}^{3}$, assuming the preferred values of the other equation of state parameters for a perrovskite structure assemblage, compared with $3.94 \mathrm{~g} / \mathrm{cm}^{3}$ calculated from static compression data. The latter value is consistent with the b-axis data.

A simple averaging calculation (mass fraction weighted addition of individual axis Hugoniots) giveg in "average" forsterite Hugoniot about 0.13 $\mathrm{g} / \mathrm{cm}$ less dense than the preferred theoretical Hugoniots, in agreement with data on dense polycrystalline forsterite to $100 \mathrm{GPa}$.

Partial release paths for the a-axis experiments are very steep and are comparable to those reported by Jackson and Ahrens [1979] along the b axis. The c-axis release paths are much shallower suggesting that the samples revert to their lowpressure form rapidly upon unloading. The fact that shock compression of the a and $c$ axes produces similar Hugoniot states, but markedly different release states is further evidence for a complex shock process in single-crystal forsterite.

We have compared shock-wave data for singlecrystal forsterite with the PREM density profile in the lower mantle. Interpolated Hugoniots for Fo 8 based on the $\mathrm{Fo}_{100}$ single-crystal data and previlous data of McQueen et al. [1967] and Marsh [1980] for $\mathrm{FO}_{45}$ and $\mathrm{Fa}$ bracket the Hugoniot data of McQueen et al. [1967] for Twin Sisters dunite ( $\mathrm{Fo}_{88}$ ), suggesting a highly linear variation of olivine Hugoniots with iron content. Considering differences between shock temperatures and lower mantie temperature estimates, we conclude that an olivine stoichiometry lower mantle with $\mathrm{Mg}$ mole fraction between 0.80 and 0.89 is compatible with PREM densities. These values are lower than the Mg mole fraction estimates of 0.90 to 0.95 of Liu [1977], Watt and O'Connell [1978], and Watt and Ahrens [1982], from extrapolation of static compression results for perovskite-structure olivine and pyroxene. This disagreement demonstrates the importance of further research on the properties of olivine and pyroxene stolchiometries at lower mantle conditions.

In three $a-$ and $b$-axis experiments at impact velocities lower than have been previously used on single-orystal forstertte, we have observed a two-wave (elastic and deformational) structure 
for the $b$ axis very similar to that of Raikes and Ahrens [1979] for the c axts; however, for the a axis, we flind a three-wave (elastic and two deformationa 1) structure. The Hugoniot elastic limits we determine are in excellent agreement with the results of Syono et al.[1981a]; however, they did not observe the complex wave structure found here, perhaps because their experiments were made at sonewhat higher impact velocities. The pressure at which the first shock wave is observed is about $9 \mathrm{GPa}$, In approximate agreement with the pressure at which the forsterite $\alpha \rightarrow \beta$ or $\gamma$ transition occurs under static conditions. This shock state and that determined from the second shock wave at 16-18 GPa are displaced to densities higher than those for the computed $F o(\alpha)$ Hugoniot by $0.05-0.15 \mathrm{~g} / \mathrm{cm}^{3}$. Thus, the mixed-phase region begins at lower pressure for the a axis than for the $b$ and $c$ axes. The Hugonlot temperature is only about $350 \mathrm{~K}$, which may indicate that the transition is not thermally activated and occurs on the short time scale of shock experiments based on a dislocation model for the transition [Polrier, 1981]. More detalled study of this apparent phase transition front is warranted.

Acknowledgments. We appreclate the careful construction and execution of these experiments by $E$. Gelle and $M$. Long and acknowledge useful discussions with G. A. Lyzenga and J. M. Vizgirda. D. L. Anderson offered helpful comments on the manuscript. We are again grateful to T. J. Shankl and for providing these crystals to us. Computing support was provided by the office of Computer Services and the Department of Geology, Rensselaer Polytechnic Institute. Supported by NSF grant EAR 80-18819. Contribution 3809, Division of Geological and Planetary Sciences, California Institute of Technolosy.

\section{References}

Ahrens, T. J., and V. G. Gregson, Shock compression of crustal rocks: Data for quartz, calcite and plagioclase rocks, J. Geophys. Res., 69, 4839-4874, 1964.

Ahrens, T. J., and C. F. Petersen, Shock wave data and the study of the Earth, in The Appl1cation of Modem Physics to the Earth and Planetary Interiors, edited by $\mathrm{s}$. K. Runcom, pp. 449-461, John Wil ey, Now York, 1969.

Ahrens, T. J., W. H. Gust, and E. B. Royce, Material strength effect in the shock compression of alumina, J. Appl. Phys., 39, 4610-4616, 1968 .

Ahrens, T. J., D. L. Anderson, and A. E. Ringwood, Equations of state and crystal structures of high-pressure phases of shocked sillcates and oxides, Rev. Geophys. Space. Phys., 7, 667$707,1969$.

Ahrens, T. J., J. H. Lower, and P. L. Lagus, Equation of state of forsterite, J. Geophys. Res., 76, 518-528, 1971.

Ahrens, T. J., T. Jackson, and R. Jeanloz, Shock compression and adiabatic release of a titanoferous basalt, Proc. Lunar. Sc1. Conf., 8th, 3437-3455, 1977.

Anderson, D. L., Petrology of the mantle, Mineral. Soc. Am. Spec. Pap., 3, 85-95, 1970.

Anderson, D. L., Composition of the mantle and core, Annu. Rev. Earth Planet. Sci., 5, 179202,1977 .
Anderson, D. L., C. Samis, and T. Jordan, Composition and evolution of the mantle and core, Science, 171, 1103-1112, 1971.

Anderson, 0. L., and P. Andreatch, Pressure derivatives of elastic constants of single-crystal $\mathrm{MgO}$ at $23^{\circ}$ and $-195.8^{\circ} \mathrm{C}$, J. Am. Ceram. Soc., 49, 404-409, 1966.

Bass, J. D., R. C. Liebermann, D. J. Weldner, and S. J. Finch, Elastic properties from acoustic and volume compression experiments, Phys. Earth Planet. Inter., 25, 140-158, 1981.

Birch, F., Elasticity and constitution of the Earth's interior, J. Geophys. Res., 57, 227286, 1952.

Birch, F., The velocity of compressional waves in rocks to 10 kilobars, 1, J. Geophys. Res., 65, 1083-1102, 1960.

Brown, J. M., and T. J. Shankland, Thermodynamic parameters in the Earth as determined from seismic proflles, Geophys. J. R. Astron. Soc., $66,579-596,198 \%$.

Burdick, L., and D. L. Anderson, Interpretation of velocity profiles of the mantle, J. Geophys. Res., 80, 1070-1074, 1975.

Butler, $\overline{R_{.}}$, and D. L. Anderson, Equation of state fits to the lower mantle, Phys. Earth Planet. Inter., 17, 147-162, 1978.

Chang, E., and E. K. Graham, The elastic constants of cassiterite $\mathrm{SnO}_{2}$ and thelr pressure and temperature dependence, J. Geophys. Res., 80, 2595-2599, 1975.

Dandekar, D. P., and A. L. Ruoff, Temperature dependence of the elastic constants of calcite between $160^{\circ}$ and $300^{\circ} \mathrm{K}$, J. App 1. Phys., 39, 6004-6009, 1968 .

Davies, G. F., Limits on the constitution of the lower mantle, Geophys. J. R. Astron. Soc., 38, 479-503, 1974.

Dzlewonsk1, A. M., and D. L. Anderson, Prelim1nary reference Earth model, Phys. Earth Planet. Inter., 25, 297-356, 1981.

Fritz, J. N., S. P. Marsh, W. J. Carter, and R. G. McQueen, The Hug on lot equation of state of sodium chloride in the sodium chloride structure, NBS Spec. Publ., 326, 201-208, 1971.

Gaffney, $E_{2+} S_{.}$, and D. L. Anderson, Effect of low spin $\mathrm{Fe}^{2+}$ on the composition of the lower mantle, J. Feophys. Res., 78, 7005-7014, 1973.

Graham, E. K., and G. R. Barsch, Elastic constants of single-crystal forsterite as a function of temperature and pressure, J. Geophys. Res., 74, 5949-5960, 1969.

Ito, E., The absence of oxide mixture in highpressure phases of Mg-silicates, Geophys. Res. Lett., 4, 72-74, 1977.

Ito, E., and H. Yamada, Stability relations of silicate spinels, ilmenites, and perovskites, In High Pressure Research in Geophysics, edited by $\mathrm{S}$. I. Akimoto and M. H. Manghnan1, pp. 405419, Center for Academic Publications, Tokyo, 1982.

Ito, K., S. Endo, and N. Kawai, Olivine-spinel transformation in a natural forsterite, Phys. Earth Planet. Int., 4, 425-428, 1971.

Jackson, I., and T. J. Ahrens, Shock wave compression of single-crystal forsterite, J. Geophys. Res., 84, 3039-3048, 1979.

Jackson, I., and H. Niesler, The elasticity of periclase to $3 \mathrm{GPa}$ and some geophysical implications, in High Pressure Research in Geophysics, edited by S. I. Akimoto and M. H. Mangh- 
nan1, pp. 93-113, Center for Academic Publications, Tokyo, 1982.

Jakubith, M., and P. Seldel, Shock-loading experiments on eclogite, Geophys. Res. Lett., 9 , 408-411, 1982.

Jeanloz, R., Shock effects in olivine and implications for Hugoniot data, J. Geophys. Res., 85, 3163-3176, 1980.

Jeanloz, R., and T. J. Ahrens, Pyroxenes and ollvines: Structural implications of shock-wave data for high-pressure phases, in H1gh-Pressure Research: Applications in Geophysics, edited by M. H. Manghnani and S. Akimoto, pp. 439-461, Academic, New York, 1977.

Jeanolz, R., and T. J. Ahrens, Release adlabat measurements on minerals: The effect of viscosIty, J. Geophys. Res., 84, 7545-7548, 1979.

Jeanloz, R., and T. J. Ahrens, Equations of state of FeO and CaO, Ceophys. J. R. Astron. Soc., $62,505-528,1980$.

Jeanloz, R., and A. B. Thompson, Phase transformations and mantle discontinuities, Rev. Geophys. Space Phys., 21, 51-74, 1983.

Jeanloz, R., T. J. Ahrens, J. S. Lally, f. L. Nord, J. M. Christie, and A. H. Heuer, Shockproduced olivine glass: First observation, Science, 197, 457-459, 1977.

King, D. A., and T. J. Ahrens, Shock compression of Ilmenite, J. Geophys. Res., 81, 931-935, 1976.

Kumazawa, M., and 0. L. Anderson, Elast 1c modul1, pressure derivatives, and temperature derivatives of single-crystal olivine and singlecrystal forsterite, J. Geophys. Res., 74, 59615972, 1969.

Liebermann, R. C., L. E. A. Jones, and A. E. Ring wood, Elasticity of aluminate, titanate, stannate, and germanate compounds with the perovskite structure, Phys. Earth Planet. Inter., 14, 165-178, 1977.

Liu, L. G., Post-oxide phases of forsterite and enstatite, Geophys. Res. Lett., ?, 417-419, 1975.

Liu, L. G., The post-spinel phase of forsterite, Nature, 262, 770-772, 1976a.

LiU, L. G., Orthorhombic perovskite phases observed in olivine, pyroxene, and garnet at high pressures and temperatures, Phys. Earth Planet. Inter., 11, 289-298, 1976b.

Liu, L. G., Mineralogy and chemistry of the Earth's lower mantle above $1000 \mathrm{~km}$, Geophys. J. R. Astron. Soo., 48, 53-62, 1977.

Liu, L., W. A. Bassett, and T. Takahashi, Isothermal compression of a spinel phase of $\mathrm{CO}_{2} \mathrm{SIO}_{4}$ and magnesian ilmenite, J. Geophys. Res., 79, 1171-1174, 1974.

Lyzenga, G. A., and T. J. Ahrens, The relation between the shook-induced free-surface velocity and the postshock specific volume of solids, J. App 1. Phys., 49, 201-204, 1978.

Lyzenga, G. A., and T. J. Ahrens, Shock temperature measurements in $\mathrm{Mg}_{2} \mathrm{SiO}_{4}$ and $\mathrm{SiO}_{2}$ at high pressures, Geophys. Res. Lett., 7, ${ }^{2} 141-144$, 1980.

Mao, H. K., T. Yagi, and P. M. Bell, Mineralogy of the Earth's deep mantle: Quenching experiments on mineral compositions at high pressure and temperature, Year Book Cameg ie Inst. Washington, 1976, 502-504, 1977 .

Marsh, S. P., Shock Hug oniot Data, University of California Press, Berkeley, 1980.
McQueen, R. G., The equation of state of $m i x-$ tures, alloys, and compounds, in seismic Coupling, Advanced Research Project Meeting, edited by G. Simmons, pp.53-106, National Technical Information Service, Springfteld, Va., 1968.

MeQueen, R. G., and S. P. Marsh, in Handbook of Physical Constants, Mem. 97, edited by S. P. Clark, pp. 153-159, Geological Society of America, Youlder, Colo., 1966.

McQueen, R. G., S. P. Marsh, and J. N. Fritz, Hugoniot equation of state of twelve rocks, J. Geophys. Res., 72, 4999-5036, 1967.

McQueen, R. G., S. P. Marsh, J. W. Taylor, J. N. Fritz, and W. J. Carter, The equation of state of sollds from shock wave studies, in $\mathrm{HIgh} \mathrm{Ve-}$ locity Impact Phenomena, edited by R. Kinslow, op. 294-419 and appendices, Academic, New York, 1970.

Polrler, J. P., on the kinetics of olivine-spinel transition, Phys. Earth Planet. Inter., 26, $179-187,1981$.

Ralkes, S. A., and T. J. Ahrens, Post-shook temperatures in minerals, Geophys. J. R. Astron. Soc., 58, 717-748, 1979.

Rice, M. H., R. G. MeQueen, and J. M. Walsh, Compression of solids by strong shock waves, Solid State Phys., 6, 1-63, 1958.

Sawamoto, H., Orthorhombic perovskite $(\mathrm{Mg}, \mathrm{Fe}) \mathrm{SiO}_{3}$ and the constitution of the lower mantle, in High-Pressure Research: Applications in Geophysics, edited by M. H. Manghnani and S. I. Akimoto, pp. 219-244, Academic, New York, 1977. Stacey, F. D., A thermal model of the Earth, Phys. Earth Planet. Inter., 15, 341-348, 1977.

Spetzler, H., Equation of state of polycrystalline and single-crystal $\mathrm{MgO}$ to 8 kilobars and $800^{\circ} \mathrm{K}$, J. Geophys. Res., 75, 2073-2087, 1970.

Suito, $\mathrm{K}_{\text {. }}$, Phase relations of pure $\mathrm{Mg}_{2} \mathrm{SiO}_{4}$ up to 200 kilobars, in High-Pressure Research: Applications in Geophysics, edited by M. H. Manghnani and S. I. Akimoto, pp. 255-266, Acaderic, New York, 1977.

Syono, Y., T. Goto, J.-I. Sato, and H. Takei, Shock compression measurements of sing le-arystal forsterite in the pressure range 15-93 $\mathrm{GPa}$, J. Geophys. Res., 86, 6181-6186, $1981 \mathrm{a}$.

Syono, Y., T. Foto, H. Take1, M. Tokonami, and K. Nobuga1, Dissociation reaction in forsterite under shock compression, Sctence, 214, 177-179, $1981 \mathrm{~b}$.

Trunin, R. F., V. I. Gon'shakova, G. V. Simakov, and N. E. Galdin, A study of rocks under the $h$ igh pressures and temperatures created by shock compression, Izv. Acad. Sci. USSR Phys. Solid Earth, Eng 1. Transl., 8, 579-586, 1965.

vassiliou, M. S., and T. J. Ahrens, Hug on iot equation of state of periclase to $200 \mathrm{GPa}$, Geophys. Res. Lett., 8 , 729-732, 1981.

Wackerle, J., Shock-wave compression of quartz, J. Appl. Phys., 33, 922-937, 1962.

Watt, J. P., and T. J. Anrens, The role of iron partitioning in mantle composition, evolution, and scale of convection, J. Geophys. Res., 87, $5631-5644,1982$.

Watt, J. P., and R. J. O'Connell, Mixed-oxide and perovskite-structure model mantles from 700$1200 \mathrm{~km}$, Geophys. J. R. Astron. Soc., 54, 601630,1978 .

Watt, J. P., and L. Peselnick, Clariflcation of the Hashin-Shtrikman bounds on the effective elastic moduli of polycrystals with hexagonal, 
trigonal, and tetragonal symmetries, J. Appl. Phys., 51, 1525-1531, 1980.

Weidner, D. J., J. D. Bass, A. E. Ringwood, and W. Sinclatr, The single-crystal elastic moduli of stishovite, J. Geophys. Res., 87, 4740-4746, 1982 .

Yagi, T., H. K. Mao, and P. M. Bell, Isothermal compression of perovskite-type MgSiO , Year Book Carnegie Inst. Washington, 1977, 835-837, 1978 .

Yag1, T., H. K. Mao, and P. M. Bell, Lattice parameters and spect fl $c$ volume for the perovskd te phase of or thopyroxene composition ( $\mathrm{Mg}, \mathrm{Fe}$ ) SiO in Year Book Carnegie Inst. Washington, 1978, $612-613,1979 a$.
Yagi, T., H. R. Mao, and P. M. Bell, Hydrostatic compression of $\mathrm{MgSiO}_{3}$ of perovskite structure, Year Book Carnegie Iñst. Washington, 1978, 613$614,1979 b$.

T.J.Ahrens, Seismological Laboratory, California Institute of Technology, Pasadera, CA 91125. J.P.Watt, Department of Geology, Rensselaer Polytechnic Institute, Troy, NY 12181.

$$
\begin{gathered}
\text { (Received September 23, 1982; } \\
\text { revised June 2, 1983; } \\
\text { accepted, June 16, 1983.) }
\end{gathered}
$$

